\begin{tabular}{|c|c|}
\hline \multirow{3}{*}{ 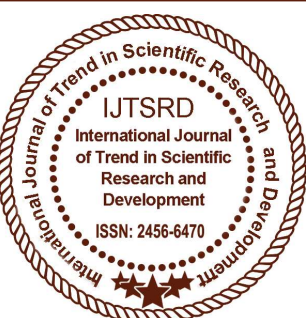 } & $\begin{array}{l}\text { International Journal of Trend in Scientific } \\
\text { Research and Development (IJTSRD) }\end{array}$ \\
\hline & International Open Access Journal \\
\hline & ISSN No: 2456 - 6470 | www.ijtsrd.com | Volume - 2 | Issue - 5 \\
\hline
\end{tabular}

\title{
Analyses of Some Engineering Properties of Ado-Ekiti to Ilawe-Ekiti Road Soil, Southwestern Nigeria
}

\author{
Samuel O. Akinlolu, Adeyemi E. Adetoro \\ Lecturer, Department of Civil Engineering \\ The Federal Polytechnic, Ado-Ekiti, Nigeria
}

\begin{abstract}
This study sought to analyze the Engineering properties of Ado-Ekiti to Ilawe-Ekiti road soil. Soil samples were taken from three locations within the study area to laboratory for Atterberg Limits, Particle Size Distribution and Permeability tests. Results showed that the Liquid Limit (LL), Plasticity Index (PI), Shrinkage Limit (SL) and Permeability values varied from 28.48 to $32.50 \%, 12.03$ to $23.60 \%, 0.6$ to $0.72 \%$ and $5.14 \times 10-5$ to $1.08 \times 10-3 \mathrm{~mm} / \mathrm{s}$ respectively for all the soil samples. Their clay or silt, sand and gravel also ranged from 15.3 to $34.1 \%, 48.1$ $-77.2 \%$ and $3.8-13.6 \%$ respectively. The soil samples were generally and grouply classified as granular and A - 2 - 6 materials with mainly silty or clayey gravel and sand constituent materials. All the soil samples were good as subgrade, subbase and base materials. However, they have low permeability, which showed the reason for road failure in their locations. It is recommended that further study should be carried out.
\end{abstract}

Keywords: Atterberg Limits; Base; Particle Size Distribution; Permeability; Subbase; Subgrade.

\section{INTRODUCTION}

Road materials are typically characterized by their strength and stiffness. Capillary action and moisture vapour movement are also responsible for water accumulation beneath a pavement structure. The effect of water on the structural support of the pavement system is due to saturated fine-grain roadbed soil, which could experience modulus reduction of more than $50 \%$. If the sub-grade permeability is less than $3 \mathrm{~m} /$ day (10ft/day), some form of subsurface drainage or other design features to combat potential moisture banes should be considered ([7], [9]).
Road performance is governed by quality of its subgrade and sub-base layers. The sub-grade and subbase layers which acted as the road's foundation have a major responsibility of guiding against the detrimental influences of climate and traffic stresses. Thus, there is need to build a stable sub-grade and a properly drained sub-base which would result in construction of an effective and long lasting pavement system ([7], [9]).

Distress problems are majorly caused by excess water in the pavement structure. Water reduces the strength of unbounded granular materials and sub grade soils. It causes bumping of concrete pavements with subsequent faulting, cracking and general shoulder deterioration. Pumping of fines in the flexible pavements base course may also occur with resulting loss of/support due to high hydrodynamic pressure generated by traffic movement. It also causes differential heaving over swelling soils. Continuous contact with water causes stripping of asphalt mixture ([7], [9]).

Past research works showed that the better way(s) to assess road pavement materials in order to avoid above stated roads problems due to water is through proper analyses of the soil's engineering properties using tests such as California Bearing Ratio (CBR), Particle size, liquid limits among others ([1], [2], [7]). This study sought to analyze some engineering properties of Ado-ekiti to Ilawe-ekiti road soil, Southwestern Nigeria. The tests carried out were Atterberg Limits, Particle Size Permeability. These helped in classification, analyses of mechanical properties and permeability of the road soil, thus proffer solution to the road's failure. 


\section{A. Study Area}

The study area is along Ado Ekiti - Ilawe Ekiti road linked Ado - Ekiti and Ilawe - Ekiti Local Government Areas (LGAs) together within Ekiti State and in extension, linked Ekiti State to Ondo and Osun States. It is about $17.5 \mathrm{~km}$ and lies within Latitude 70 $35^{\prime} 60^{\prime \prime} \mathrm{N} / 7^{\circ} 37^{\prime} 16^{\prime \prime} \mathrm{N}$ and Longitude $5005^{\prime} 60^{\prime \prime} \mathrm{E} /$ $5^{\circ} 13^{\prime} 17^{\prime \prime}$ E as shown in Fig. 1. The geology of Ekiti State where the study area is situated consists of old plains broken by steep sided outcropping dome rocks and underlain by metamorphic rocks of the Precambrian basement complex of South western
Nigeria, which are very old. These showed serious changes in grain size and mineral composition. The rocks are quartz gneisses and schists consisting mainly quartz with small amounts of white mizageous minerals. They vary from very coarse-grained pegmatite to medium-grained gneisses in grain size and structure. They are strongly foliated and occur as outcrops. The soils derived from the basement complex rocks are mostly well drained, having medium to coarse in texture ([2], [3], [6]).

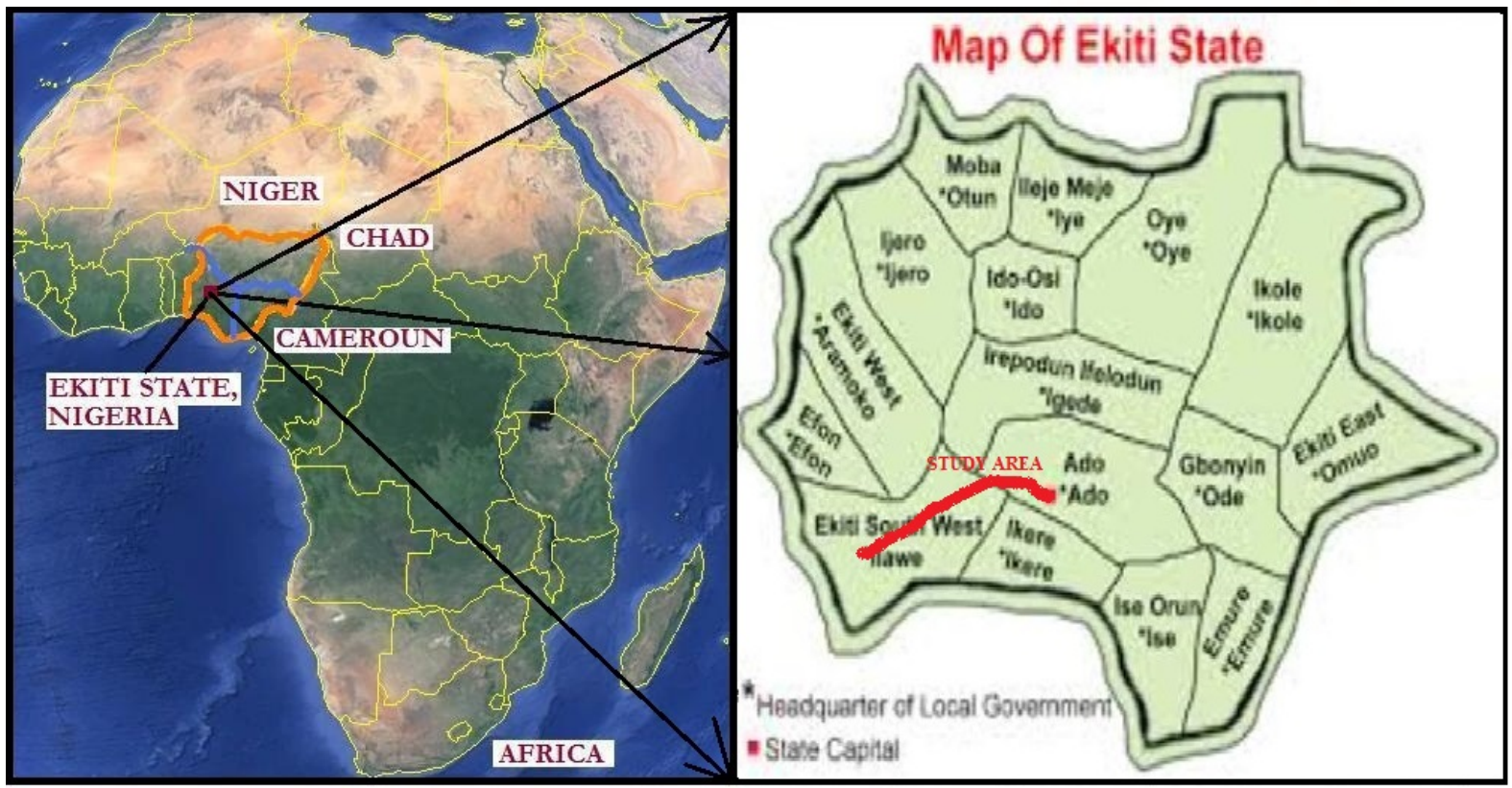

\section{B. Atterberg Limits Tests}

This is a set of tests, which comprises of Liquid Limits (LL), Plastic Limit (PL) and Shrinkage Limit tests. Plasticity Index can be determined from the limits using the formula PI = LL $-\mathrm{PL}$. Another name for this set of tests is Consistency Limits Tests. The tests usually showed spontaneous reactions of soil samples with water, which are used for soils' classification and analyses of mechanical properties of road fill materials. The results were graded / classified in accordance with [4], [8] and other standards [6].

\section{Particle Size Distribution Test}

This test is used for analyses of soil particles distribution. Soil particles were grouped into sizes and relative proportion by weight (i.e. clay, sand and gravel fraction). It is usually used for road fill material. The results are usually classified with reference to [4] and other classification methods [3].

\section{Permeabilty Test}

Permeability test is always used in the analysis of permeability in landfill and road construction soils and is measured using many methods including Constant and Falling Heads laboratory tests. Permeability can be determined in the field using insitu borehole permeability and field pumping tests. Coefficients of permeability can be experimentally derived from the results of Particle size distribution laboratory test [7].

\section{Materials and Methods}

Soil samples were taken at random from three locations (where there are potholes i.e. road failure) along the road at precise depth of $0.90 \mathrm{~m}$ after topsoil removal using method of disturbed sampling. The soil samples collected were stored in polythene bag to maintain its natural moisture contents. The samples were then taken to the laboratory where the deleterious materials such as roots were removed. The samples were air-dried and large particles were 
removed. The chainages of the collected soil samples locations were recorded. The details of the soil samples were as shown in Table 1. Moulding of test specimens was started as soon as possible after completion of identification. Their attributes were also examined. All tests were performed to standards in accordance with [5]. The results were then compared with the standard specified values and grouped with reference to [4], [8].

Coefficient of Uniformity $\left(\mathrm{C}_{\mathrm{u}}\right)$ was calculated from the Particle size grading curve using Hazen formula as shown in equation (1).

$\mathrm{C}_{\mathrm{u}}=\mathrm{D}_{60} / \mathrm{D}_{10}$

Where $\mathrm{D}_{60}$ and $\mathrm{D}_{10}$ were obtained from the grading curve and it corresponds to the percentage passing at 60 and $10 \%$ respectively in $\mathrm{mm}$. When $\mathrm{C}_{\mathrm{u}}>5$, it indicates a well graded soil, while $\mathrm{C}_{\mathrm{u}}<3$ indicates a uniform soil. Permeability was calculated using McKinley formula as shown in equation (2).

$\mathrm{K}=\mathrm{CD}^{2}{ }_{50}$

Where $\mathrm{K}$ is permeability $(\mathrm{mm} / \mathrm{sec}), \mathrm{C}$ is McKinley's constant which is approximately 0.00357 and $\mathrm{D}_{50}$ is maximum diameter of the smallest 50 percent of the sample.
Table 1: The Details of the Soil Samples

\begin{tabular}{|c|c|c|c|}
\hline $\begin{array}{c}\text { SAMIPLE } \\
\text { CODE }\end{array}$ & $\begin{array}{l}\text { LOCA } \\
\text { TION }\end{array}$ & DESCRIPTION & $\begin{array}{c}\text { CHAIN } \\
\text { AGE }\end{array}$ \\
\hline A & 1 & $\begin{array}{l}\text { Sample from } \\
\text { pothole at the } \\
\text { centre of the } \\
\text { Road }\end{array}$ & $0+350$ \\
\hline $\mathrm{B}$ & 2 & $\begin{array}{l}\text { Sample from } \\
\text { depression / rut } \\
\text { at the right hand } \\
\text { side of the Road }\end{array}$ & $7+200$ \\
\hline $\mathrm{C}$ & 3 & $\begin{array}{l}\text { Sample from } \\
\text { pothole at the } \\
\text { left hand side of } \\
\text { the road }\end{array}$ & $10+500$ \\
\hline
\end{tabular}

\section{Results and Discussion}

Field assessment showed that there are presence of cracks, depression, potholes and ruts along the road, which could be due to pavement layers' failure because the road is well drained. The shoulders are mostly overgrown with vegetation. Generally, there are signs of lack of maintenance along the road.

Table 2 showed Particle size analysis test results for the soil samples obtained from the road. It is observed that all the soil samples have large quantities of clay or silt (i.e. $>14 \%$ ). Sample B has required sand (i.e. 43 to $51 \%$ ), while samples $\mathrm{A}$ and $\mathrm{C}$ have more than required sand (i.e. $>51 \%$ ). None of the soil samples has the required quantities of sand (i.e. 32 to $37 \%$ ).

Table 2: Particle Size Analysis Test Results for the Soil Samples Obtained From the Road

\begin{tabular}{|c|c|c|c|c|c|c|c|c|c|}
\hline SIEVE & \multicolumn{3}{|c|}{$\%$ PASSING } & \multicolumn{2}{|c|}{ LIMITS } & \multicolumn{3}{|c|}{ SOIL CLASSN. } & \multirow[t]{2}{*}{ SOIL TYPE } \\
\hline No. $(\mathrm{mm})$ & A & B & C & LOWER & UPPER & A & B & C & \\
\hline 12.5 & 100 & 100 & 100 & 100 & 100 & & $C$ & & \\
\hline 9.5 & 96.3 & 93.3 & 99.8 & 87 & 97 & \multirow{2}{*}{3.8} & \multirow[t]{2}{*}{11.1} & \multirow[t]{2}{*}{13.6} & \multirow[t]{2}{*}{ GRAVEL } \\
\hline 4.25 & 95.6 & 86.6 & 94.6 & 65 & 82 & & & & \\
\hline 2.36 & 92.5 & 82.2 & 86.2 & 50 & 65 & \multirow[t]{5}{*}{77.2} & \multirow[t]{5}{*}{48.1} & \multirow[t]{5}{*}{63.8} & \multirow[t]{5}{*}{ SAND } \\
\hline 1.18 & 77.0 & 79.1 & 64.8 & 36 & 51 & & & & \\
\hline 0.6 & 53.1 & 74.2 & 57.7 & 26 & 40 & & & & \\
\hline 0.3 & 34.1 & 66.4 & 42.1 & 18 & 30 & & & & \\
\hline 0.15 & 19.1 & 58.8 & 30.9 & 13 & 24 & & & & \\
\hline 0.075 & 15.3 & 34.1 & 22.4 & 7 & 14 & 15.3 & 34.1 & 22.4 & SILT/CLAY \\
\hline
\end{tabular}

Generally, the quantities of clay or silt present in the soils were in descending orders of $\mathrm{B}>\mathrm{C}>\mathrm{A}$. The quantities of sand present in the soils follow the descending orders of $\mathrm{A}>\mathrm{C}>\mathrm{B}$. While $\mathrm{C}>\mathrm{B}>\mathrm{A}$

were in descending order for gravel quantities of the soils. All the soil samples have percentages finer than $0.075 \mathrm{~mm}$ fractions less than $35 \%$ (i.e. $<35 \%$ ).
Table 3: Atterberg Limit Tests Results for the Soil Samples

\begin{tabular}{|l|c|c|l|}
\hline \multicolumn{1}{|c|}{ ATTERBERG LIMITS } & \multicolumn{3}{|c|}{ SAMPLES CODE } \\
\hline & A & B & \multicolumn{1}{c|}{ C } \\
\hline LIQUID LIMIT (\%) & 28.48 & 32.10 & 32.50 \\
\hline PLASTIC LIMIT (\%) & 16.45 & 19.90 & 8.90 \\
\hline PLASTICITY INDEX (\%) & 12.03 & 12.20 & 23.60 \\
\hline
\end{tabular}




\begin{tabular}{|l|l|l|l|}
\hline SHRINKAGE LIMIT (\%) & 0.60 & 0.70 & 0.72 \\
\hline
\end{tabular}

From Table 3, all the Liquid Limit (LL) values for the soil samples were less than $40 \%$. While all the soil samples have the Plasticity Indices (PI) values greater than $11 \%$. Hence, according to [4], they were generally classified as granular materials with general rating as sub-grade materials of excellent to good. Their percentage ranges of sand and gravel were 48.1 $-77.2 \%$ and $3.8-13.6 \%$ respectively. These results implied that the soils have large contents of silty or clay and sandy materials. Thus, they have significant constituent materials of silty or clayey Gravel and Sand soils and grouply classified as A - 2 - 6 soil.

It is also observed that the Liquid Limit (LL), Plasticity Index (PI) and Shrinkage Limit (SL) values varied from 28.48 to $32.50 \%, 12.03$ to $23.60 \%$ and 0.6 to $0.72 \%$ respectively for all the soil samples. Generally, all the soil samples met the required specification for subgrade (i.e. $\mathrm{LL} \leq 80 \%, \mathrm{SL} \leq 0.8 \%$ and $\mathrm{PI} \leq 55 \%$ ), base and subbase (i.e. $\mathrm{LL} \leq 35 \%, \mathrm{SL} \leq$ $0.6 \%$ and $\mathrm{PI} \leq 12 \%$ ) course materials in accordance with [8], thus suitable for them.

Table 4: Results of Coefficient of Uniformity (Cu) and Permeability (K) Using Particle Size Distribution

\begin{tabular}{|c|c|c|c|c|c|c|c|}
\hline Sample & $\mathbf{D}_{60}(\mathrm{~mm})$ & $\mathbf{D}_{10}(\mathrm{~mm})$ & $\mathrm{Cu}$ & $\mathbf{D}_{50}(\mathrm{~mm})$ & $\mathbf{D}_{50}^{2}(\mathrm{~mm})$ & $\mathrm{K}(\mathrm{mm} / \mathrm{sec})$ & Grading Type \\
\hline $\mathrm{A}$ & 0.75 & 0.03 & 25 & 0.55 & 0.3025 & $1.08 \mathrm{E}-03$ & Well graded \\
\hline $\mathrm{B}$ & 0.175 & 0.04 & 4.375 & 0.12 & 0.0144 & $5.14 \mathrm{E}-05$ & Not well graded \\
\hline $\mathrm{C}$ & 0.75 & 0.03 & 25 & 0.42 & 0.1764 & $6.30 \mathrm{E}-04$ & Well graded \\
\hline
\end{tabular}

From Table 4 , the permeability $(\mathrm{K})$ values obtained ranges from $5.14 \times 10^{-5}$ to $1.08 \times 10^{-3} \mathrm{~mm} / \mathrm{s}$, which showed that their permeability is very low (i.e. $\mathrm{K}<$ $10^{-1} \mathrm{~cm} / \mathrm{sec}$.). Soil samples A and $\mathrm{C}$ were well-graded soil (i.e. $C_{u}>5$ ), while soil sample $B$ was not. The low permeability showed that the soils in the study locations retain water, which suggests that there is presence of large contents of clay or silt in the soil ([7], [10]). Therefore, the soil becomes plastic under road traffic pressure, which resulted in pavement failure in the selected location along the road. The permeability of the soil samples is in descending order of $\mathrm{A}>\mathrm{C}>\mathrm{B}$.

\section{Conclusion}

The analyses of mechanical and permeability properties of Ado-ekiti to Ilawe-ekiti road soil have shown that all the soil samples were generally classified as granular material with mainly silty or clayey gravel and sand constituent materials. They were grouply classified as A $-2-6$ and excellent to good as subgrade, base and subbase materials. All the soil samples have low permeability, which indicated the reason for road failure(s) around them. It is recommended that further study should be carried out.

\section{References}

1. Adams, J. O. and Adetoro, A. E. "Analysis of Road Pavement Failure caused by Soil Properties along Adoekiti - Akure Road, Nigeria,"

International Journal of Novel Research in Engineering and Applied Sciences (IJNREAS), vol. 1(1), pp. 1-7, 2014a.
2. Adetoro, A. E. and Akinwande, J. T., "Assessment of some Pavement Indices of Ado Ekiti - Akure Road, South-Western Nigeria," International Journal of Novel Research in Engineering and Applied Sciences (IJNREAS), vol. 1(1), pp. 1-7, 2014.

3. Adetoro, A. E. and Dada, O. M., "Comparative Analyses of Mechanical Properties of Ekiti State Soil, Nigeria," Journal of Multidisciplinary Engineering Science and Technology (JMEST), vol. 4(5), pp. $7272-7276,2017$.

4. American Association of State Highway and Transportation Officials - AASHTO, "Standard Specification for Transportation Materials and Methods of Sampling and Testing (14th Edition)," USA, Washington DC: AASHTO, 1986.

5. British Standard 1377 - BS 1377, "British Standard Methods of Test for Soils for Civil Engineering Purposes," UK, London: British Standards Institution, 1990.

6. Ekiti State Directorate of ICT, "The Official Website of the Government of Ekiti State, Nigeria,"

https://ekitistate.gov.ng/administration/local-govt/, 20 June, 2018.

7. Elhakim, A. F. "Estimation of Soil Permeability," Alexandria Engineering Journal, vol. 55, pp. 2631 $-2638,2016$. 
8. Federal Ministry of Works and Housing FMWH, "General Specification (Roads and Bridges) - Revised Edition, vol. 2, Nigeria," Abuja: Federal Ministry of Works and Housing, 1997.

9. Ifada, P. T., Kasali, I. A., Makanjuola, P. I. and Monye, O. A. "Assessment of Permeability Characteristics of Sub-Grade Soil along Failed
Sections of Ado-Ikere Road, South-Western Nigeria," Nigeria, Ado-ekiti, The Federal Polytechnic, Dept. of Civil Engineering: HND Dissertation (Unpublished), 2015.

10. Ola, S. A, "Essentials of Geotechnical Engineering," Nigeria, Ibadan, Jericho: University Press Plc, 2013.

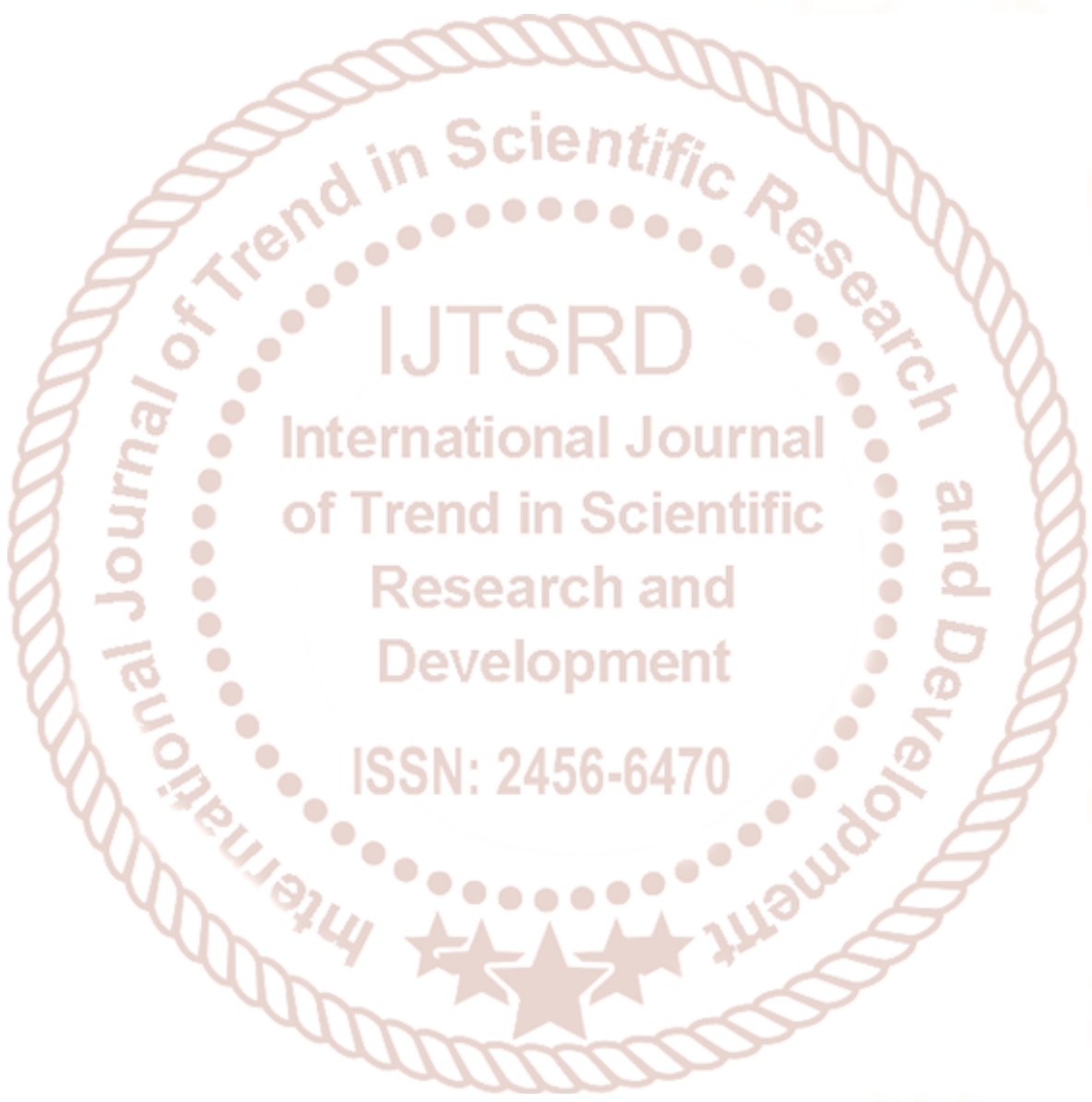

